\title{
ANÁLISE DE DISCURSO APLICADA A INVESTIGAÇÃO QUALITATIVA: PERSPECTIVA METODOLÓGICA EM DEBATE
}

\author{
Gleny Terezinha Duro Guimarães ${ }^{1}$, Marlubia Correa de Paula ${ }^{2}$ e Wanda Griep Hirai ${ }^{3}$ \\ ${ }^{1}$ Universidade Católica do Rio Grande do Sul, Brasil. gleny@pucrs.br \\ ${ }^{2}$ Universidade Estadual de Santa Cruz, Brasil. mcpaula@uesc.br \\ ${ }^{3}$ Universidade Federal de Alagoas, Brasil. wanda.hirai@gmail.com
}

\begin{abstract}
Resumo. Na análise de discurso de inspiração pecheutiana não existe um procedimento metodológico preestabelecido, o que pode gerar uma incerteza quanto à sua aplicação. Neste tipo de investigação, são os pressupostos teóricos que determinam os procedimentos metodológicos, ficando a cargo do analista traçar o seu próprio percurso. Porém, nem sempre esse processo é visualizado na investigação. Ao refletir sobre este aspecto, o presente trabalho tem o objetivo de problematizar a existência explícita ou não de uma metodologia de investigação na $A D$ e de identificar os principais elementos metodológicos que são apontados por analistas do discurso. Trata-se de uma investigação bibliográfica de cunho qualitativo, cujo método investigativo é apoiado no materialismo histórico, e o corpus, por seu turno, constituído por seis artigos científicos. O procedimento de análise incluiu a realização de um mapeamento buscando as regularidades e singularidades no material analisado. Os resultados apontam para dois tipos de interpretação metodológica: um de forma genérica, que não explicita o procedimento empregado; e o outro que dá visibilidade ao método. $\mathrm{O}$ artigo conclui que é possível descrever um procedimento metodológico de análise, não como aplicação de uma técnica, mas como um processo de investigação em que o dispositivo teórico é indissociável do analítico.
\end{abstract}

Palavras-chave: Análise de Discurso; Michel Pêcheux; Metodologia de Investigação; Investigação Qualitativa

\section{DISCOURSE ANALYSIS APPLIED TO QUALITATIVE RESEARCH: METHODOLOGICAL PERSPECTIVE IN DEBATE}

\begin{abstract}
In Michel Pêcheux's discourse analysis (DA) there is no pre-established methodological procedure, which may generate uncertainty regarding its application. In this type of investigation, it is the theoretical assumptions that determine the method, leaving it to the analyst to trace his path. However, this process is not always visualized in the investigation. When reflecting on this aspect, the present work aims to problematize the explicit existence (or not) of a research methodology in DA and to identify the main methodological elements that are pointed out by discourse analysts. This is a qualitative-bibliographic investigation that uses as a method the historical materialism. The corpus was made up of six scientific articles. The analysis procedure included the realization of a mapping seeking regularities and singularities in the analyzed material. The results point to two types of methodological interpretation: one is a "generic way", without explaining the procedure performed; and the other, giving visibility to it. The article concludes that it is possible to describe a methodological analysis procedure; not as an application of a technique, but as an investigation process in which the theoretical device is inseparable from the analytical one.
\end{abstract}

Keywords: Discourse Analysis; Michel Pêcheux; Research Methodology; Qualitative Research

\section{INTRODUÇÃO}

A investigação qualitativa tem a característica de romper com a racionalidade cartesiana que tem caracterizado tradicionalmente as investigações de cunho quantitativo, ao considerar 
que o rigor científico ocorre apenas por meio da objetividade, neutralidade e validação numérica. $\mathrm{Na}$ abordagem qualitativa, toda escolha e interpretação do analista são imbuídas de um posicionamento político e ético. O que configura, por sua vez, uma determinada concepção de homem e de sociedade, que acaba por determinar o ethos investigativo.

O presente estudo ${ }^{1}$ faz um recorte investigativo, em relação à metodologia de análise dos dados, na pesquisa qualitativa. Ao elaborar o projeto de investigação, no que se refere aos aspectos metodológicos ${ }^{2}$, o pesquisador se depara com a necessidade de definir o tipo de análise que será utilizada. Geralmente é adotado o procedimento mais conhecido, que é a Análise de Conteúdo (AC). No entanto, existe outra possibilidade, que é a Análise de Discurso (AD).

O termo análise de discurso pode ser considerado como um grande "guarda-chuva", em que, quando aberto, pode-se constatar uma estrutura feita de muitas hastes. Cada haste de sustentação poderia representar uma corrente epistemológica, com autores, conceitos e teorias diferentes, mas estando sob a identidade da análise de discurso.

Este estudo enfoca especificamente a $A D$ da linha francesa, inspirada por Michel Pêcheux, doravante referida como Análise de discurso pecheutiana (ADP). Não a estamos chamando apenas de "Análise de discurso de linha francesa", pois existem outros franceses que se dedicam a este tipo de análise. Um exemplo deles é Maingueneau, contemporâneo de Pêcheux, que em muitos aspectos dele diverge, trilhando, assim, um caminho teórico próprio. Outro desses autores que adotam uma abordagem particular da Análise de Discurso é Fairclough, desenvolvedor da corrente de análise crítica do discurso. Ainda podemos citar Patrick Charaudeau, que desenvolve a Teoria Semiolinguística de Análise de discurso, entre outros autores (Oliveira, 2013). Todos apresentam aspectos caracterísitcos que os diferenciam, e cabe ao analista de discurso definir claramente qual o autor a que ele se filia, para não incorrer numa "indisciplina intelectual ${ }^{3 \text { " }}$ (Trivinos, 1987).

Porém, é necessário mencionar que existem semelhanças entre os autores que compartilham da $A D$, uma delas é considerar o discurso como uma prática social. Outro

\footnotetext{
1 Estamos utilizando os termos estudo e trabalho para o presente artigo, de forma a não confundir o leitor quando nos referirmos aos seis artigos científicos que compoem o corpus de análise.

${ }^{2}$ A fase da metodologia é um dos itens que estruturam o projeto de investigação. Nela se definem o método; o universo e a amostra; os instrumentos para coleta; o locus; os sujeitos; e o tipo de análise.

3 Trivinos (1987) considera indisciplina intelectual quando o pesquisador mistura diferentes teorias, sem a consciência da distinção entre elas.
} 
aspecto é levar em conta a dimensão da ideologia (embora existam diferenças conceituais entre os autores).

O enfoque de reflexão deste estudo, no entanto, não recai sobre as semelhancas e diferencas entre os autores, mas, sim, sobre a questão metodológica que caracteriza a ADP. O questionamento fundamental com que o analista de discurso se depara é: como se realiza a análise de discurso na perspectiva pecheutiana? Uma questão que não é simples de se responder, já que não existe uma única resposta para tal, nem um processo homogeneo procedimental. Isso se deve ao fato de que na ADP não existe a concepção da neutralidade do investigador. As escolhas do analista já estão carregadas de um posicionamento ideológico, político e ético imbuído nos gestos de interpretação. A partir desta questão se estabelecem dois objetivos para o presente trabalho: problematizar a existência explícita ou não de uma metodologia de investigação na Análise de discurso da linha francesa, com filiação em Michel Pecheux; e, além disso, identificar os principais elementos metodológicos que são apontados por analistas do discurso. Para responder a estes objetivos realizamos uma investigação bibliográfica de cunho qualitativo, cujo método investigativo é apoiado no materialismo histórico, sendo que o corpus foi constituído por seis artigos científicos. 0 procedimento de análise incluiu a realização de um mapeamento buscando as regularidades e singularidades no material analisado.

Existe aí um compromisso político, o qual, inevitavelmente, o investigador assume ao conceber o dispositivo de análise na ADP, pois se coloca "diante da realidade social em que vive, ao pensar a metodologia de análise, [e] não pode colocar-se como um copista reafirmador de posicionamentos da elite política e mercantil" (Mittman, 2007, p. 154). Em outras palavras, o analista de discurso apresenta um posicionamento crítico diante da realidade, assumindo um compromisso ético e se opondo às formas de exploração humana, por conseguinte, às desigualdades sociais decorrentes do avanço do capitalismo predatório. Aliás, a ADP se origina da análise de discursos políticos, o que significa dizer que a ADP implica num posicionamento político diante das relações e condições de produção da sociedade.

Após a contextualização do recorte investigativo do presente estudo, passamos a desenvolvê-lo nos seguintes aspectos: o dispositivo teórico-analitico da ADP; os aspectos históricos na constituição metodológica na $A D$; o dispositivo teórico para o processo metodológico na AD; a metodologia de investigação; o mapeamento do processo metodológico do corpus e os resultados alcançados. 


\section{ANÁLISE DE DISCURSO APLICADA A INVESTIGAÇÃO QUALITATIVA: DISPOSITIVO TEÓRICO-ANALÍTICO}

Pêcheux considera o discurso como resultante dos processos históricos e ideológicos em que a língua se materializa. A fala não é o discurso, pois este se caracteriza como um conceito mais amplo e complexo, em que um dos pilares do método é o materialismo histórico, no qual "todo o processo discursivo se inscreve numa relação ideológica de classes" (Pêcheux, 1997, p. 92).

O objeto da ADP é o discurso (Pêcheux, 1997). Complementa Courtine (2016) que o discurso enquanto materialidade está entre a linguística e ideologia, o que provoca a possibilidade de o dizer ter sempre outros sentidos, pois todo dizer provém de determinadas condições de produção e de diferentes formações, sejam elas sociais, ideológicas e/ou discursivas.

Portanto, o discurso não deve ser compreendido como sendo a análise de uma fala ou mesmo ser tomado como análise semântica e sintática (linguística), ou como uma unidade de análise. Sua concepção é mais ampla, pois os sentidos do discurso decorrem das estruturas materiais que determinam o modo e as relações de produção da sociedade em que são produzidos. O discurso não deve ser compreendido como um texto ou um pronunciamento e pode ser analisado sob qualquer forma de expressão (oral, verbal, icônica, corporal, artística, cultural, política, religiosa, imagética, fílmica, fotográfica, de rótulos e outros diferentes tipos de mídia etc).

A teoria da ADP se assenta epistemologicamente no tripé da língua (advinda da linguística), do materialismo histórico e da psicanálise, resultando num dispositivo teórico próprio. Este dispositivo está imbricado ao dispositivo metodológico de análise. "Tais proposições teóricas devem conduzir ao estabelecimento dos procedimentos que venham a realizar a montagem instrumental, sob a forma de um dispositivo num campo metodológico" (Courtine, 2016, p. 15).

Na ADP não é possível separar o arsenal teórico do analítico, pois a análise é processual todos os seus pressupostos devem estar interligados. Isso rompe com a ideia de que existe um procedimento escalar, etapista, cuja análise seria a última fase da investigação. Pelo contrário, a análise se faz presente desde o momento em que pensamos no problema de 
investigação; seus objetivos, a seleção do corpus, os instrumentos, ou seja, todos os elementos constitutivos da investigação estão permanentemente correlacionados.

\subsection{Aspectos históricos na constituição do processo metodológico na AD}

É importante destacar que o dispositivo de análise na ADP vem constantemente sofrendo alterações, o que significa dizer que esta é uma teoria em constante movimento. Em consequência disso, a ADP é coerente com a abordagem materialista, em que tudo se transforma, tornando concreta a possibilidade de o sentido ser sempre outro. O discurso é e está sempre em movimento. É uma teoria inacabada, ou seja, que se reconstrói de acordo com as condições de produção materiais da própria história.

A ADP se inicia no final da década de 1960, com o propósito de romper com a visão estruturalista da língua, inspirada pelos estudos do linguista e filósofo suíço Ferdinand de Saussure. Em 1969, Pêcheux, junto com seu grupo de estudos, propõe a "análise automática do discurso", doravante chamada AAD-69. Metodologicamente, foi desenvolvida ao modo de um programa de computador o que, na época, era inovador e tinha o propósito de se diferenciar da análise de conteúdo e da análise linguística. Genericamente, se constituiu pelo procedimento de inserir no computador uma lista de enunciados equivalentes, no sentido parafrástico, ao mesmo tempo em que relacionava as condições de produção e a cultura. "Essas classes de paráfrase eram o que constituía a base estável e homogênea das sequências discursivas retiradas do corpus de análise estabelecido por condições de produção igualmente estáveis e homogêneas" (Fernandes e Vinhas, 2019, p. $3)$.

Com o avanço da teoria da ADP, esse procedimento metodológico foi abandonado, na medida em que não dava conta da ideologia, nem das formações discursivas. A partir da década de 1980, com a evolução da teoria, optou-se por não seguir um procedimento metodológico, evitando, assim, uma padronização no processo e procurando dar conta do avanço teórico da ADP. O norte do dispositivo de análise passa a ser a aplicação da própria teoria. O fato de não haver uma padronização é ainda hoje uma dificuldade para os adeptos da análise de discurso, tanto em sua compreensão quanto em sua aplicação. No entanto, isso não é propriamente um problema, mas, sim, uma necessidade que acena para a importância deste debate. Após a morte de Pêcheux, em 1983, a ADP foi impulsionada, principalmente no Brasil. Sendo inicialmente implantada com ajuda das contribuições 
teóricas da linguista e professora universitária Eni de Lourdes Puccinelli Orlandi, da UNICAMP, e posteriormente expandida em todo território nacional, de forma institucionalizada. Atualmente, a discussão sobre o processo metodológico da ADP está em pauta, não no sentido de se retomar a AAD-69, mas de evidenciar novas formas de compreensão deste processo.

\subsection{Dispositivo teórico para o processo metodológico na Análise de discurso}

O processo metodológico da ADP é diversificado e variado, não existindo um padrão hegemônico de sua aplicabilidade. Apesar de não existir uma sequência de etapas, existem pressupostos teóricos que norteiam as escolhas metodológicas do analista de discurso, permitindo ao investigador que o dispositivo analitico se re-configure constantemente. Estes postulados, espécie de "fio condutor" (Mittman, 2007, p. 155) acabam de forma direta ou indireta caracterizando o processo metodológico da ADP, a partir de conceitos ${ }^{4}$ que claramente estão relacionados ao dispositivo analitico.

O primeiro desses conceitos é o de condições de produção do discurso, que significa considerar o tempo e o espaço histórico em que todo o dizer é produzido. Por exemplo, o termo "democracia" no período da ditadura brasileira tinha um sentido diferente do que se pode dizer hoje ao utilizá-lo. Podemos afirmar que os elementos históricos e ideológicos estão na base de constituição do discurso. Sendo o materialismo histórico um dos pilares da ADP, as condições de produção implicam considerar a formação social capitalista, ou seja, o modo de produção e as relações sociais e econômicas de produção da sociedade em que o dizer é produzido. "A noção de condições de produção do discurso regula, em $A D$, a relação entre a materialidade linguística de uma sequência discursiva e as condições históricas que determinam sua produção" (Courtine, 2016, p. 20). As condições de produção irão determinar as condições de existencia do dizer, o que repercute na escolha do corpus de análise.

Corpus discursivo é um "conjunto de sequências discursivas dominadas por um determinado estado, suficientemente homogêneo e estável, das condições de produção do discurso" (Courtine, 2016, p. 20). Estas condições incidem nas paráfrases (Pêcheux, 1997, p. 290), segundo conceito que destacamos nesta investigação. Sobre este aspecto, afirma Pêcheux (1997, p. 290) que a paráfrase é "histórico-discursiva para marcar a inscrição necessária dos

\footnotetext{
${ }^{4}$ Selecionamos alguns conceitos, considerando que neste trabalho não seria possível dar conta de todos.
} 
funcionamentos parafrásticos em uma formação discursiva historicamente dada". A paráfrase pode ser compreendida como enunciados diferentes, mas que de certa forma produzem significados semelhantes, permitindo caracterizar as formações discursivas.

Desta forma, o analista, ao identificar as paráfrases que caracterizam o dizer relacionado a um discurso, necessita levar em consideração os sentidos produzidos a partir das condições de produção. Isto é o que permite a ele caracterizar o funcionamento das formações discursivas (FD). A FD é outro conceito central na ADP e se caracteriza por "aquilo que pode e deve ser dito" (Pêcheux, 1990, p. 11) numa determinada formação social em que o discurso é produzido. Esta formação tem a tendência de agrupar os sentidos semelhantes no seu interior, por isso a paráfrase se consolida como uma existência necessária. Pêcheux (1990) não se refere a um sentido homogeneizador, mas ao processo que evoca regularidades discursivas, aproximando semelhanças, o que permite uma certa caracterização das formações discursivas. Todos estes conceitos também se relacionam aos de ideologia e de formações ideológicas.

Para a realização metodológica, o analista de discurso realiza gestos de interpretação. A interpretação é compreendida como um processo que vai além das fronteiras da descrição. A descrição é importante, mas por si só não é suficiente para que o analista proceda com a interpretação. A interpretação implica na tomada de posição (Pêcheux, 2002). Os gestos de interpretação que caracterizam o dispositivo de análise somente ocorrem numa correlação com o dispositivo teórico; ou seja, não há interpretação sem a teoria que a sustente. Por isso, o objeto de análise é também o objeto teórico.

Essa relação determina a constituição do corpus de análise, dos recortes das sequências discursivas que serão analisadas, e dos agrupamentos ou dispersões decorrentes desse processo. O processo metodológico pode ser comparado à constituição de uma rede em que os nós de sustentação são os conceitos teóricos, todos interligados, e os espaços entre os mesmos seriam os gestos de interpretação do objeto empírico, tendo a consciência que sempre poderá haver outros sentidos produzidos. Desse modo, a ADP permite ao pesquisador um movimento de inovação metodológica, como se a rede possibilitasse a cada analista traçar os fios que a compõe, sabendo que a rede é constituída pelo entrelacamento do dispositivo teórico com o analitico. 


\section{METODOLOGIA}

Para o desenvolvimento desta pesquisa bibliográfica utilizamos o seguinte percurso: primeiramente foi realizado um levantamento genérico na internet em que há mais de 70.000 resultados para (Discourse + analysis + methodology + Pêcheux), 24.500 para (méthodologie + d'analyse + de + discours + Pêcheux) e 60.800 para (metodologia + análise + do + discurso + Pêcheux).

Ao investigar tamanho volume de dados, foi possível constatar que havia uma imensa variedade de produções: livros (incluindo os do próprio Pecheux), artigos, dissertações e teses etc. Bem como eram listadas produções que não enfocavam o recorte do presente estudo. Diante deste universo foi necessário estabelecer alguns critérios de seleção. $O$ primeiro deles foi utilizar uma base de dados brasileira em que houvesse dissertações e teses. Para tal, consultamos o Banco Digital de Teses e Dissertações (BDTD) dos trabalhos que foram identificados por meio dos descritores "análise + de + discurso + Pêcheux". Foram encontrados 861 trabalhos, com predominância nos pós-graduação na área de letras e linguística, nos dois maiores polos de formação em ADP, a UNICAMP e a UFRGS. Com os descritores "Pêcheux + metodologia", foram apresentados 316 trabalhos. Após uma prévia consulta, constatamos que havia uma infinidade de temas, sem, no entanto, ter como objeto específico a metodologia da ADP. Partimos para o terceiro critério que era buscar artigos publicados em revistas classificadas na Scielo, que tivessem no título o descritor "metodologia + Pêcheux". Neste critério, encontrou-se apenas um trabalho. Para ampliar o corpus, o ultimo critério adotado foi: os primeiros artigos, com maior visibilidade e acessos na internet e que tivessem especificamente no título o descritor "metodologia". Outro critério adotado foi selecionar artigos em anos de publicação diferentes. Este critério é importante de ser considerado porque na teoria da ADP, a contextualização das produções discursivas se faz necessária, uma vez que se relaciona com as três épocas (Pecheux, 1983) pelas quais a ADP se configurou. Considerando todo esse percurso e critérios, delimitamos 6 artigos. Lembrando que nossa pesquisa é qualitativa e, portanto, não é a quantidade de artigos que nos interessa, mas sim a seleção daqueles que demonstravam como a metodogia da ADP havia sido construída.

Após a constituição do corpus, foi realizada a codificação ${ }^{5}$, que por questões éticas evitaria a identificação dos autores. Após várias leituras dos textos, passamos a mapear a forma

\footnotetext{
${ }^{5}$ Os artigos foram codificados com a letra A, de atigo, seguido do ano de publicação, ou seja: A/2006, A/2009, A/2011, A/2015, A/2017, A/2019.
} 
como a metodologia era abordada, ou seja, o objetivo era identificar de que forma os procedimentos de análise haviam sido realizados.

Procedemos a um mapeamento buscando identificar regularidades e singularidades no material empírico.

Além de identificar o que era comum a todos, buscamos os aspectos distintivos ou originais que poderiam estar em algum artigo. A seguir, passamos a demonstrar o resultado do mapeamento realizado sob quatro critérios, os quais foram identificados como as principais regularidades encontradas. 1. Principais conceitos da ADP utilizados na metodologia: nessa ocasião, verificamos se alguns eram nucleares para nortear a análise e se havia aprofundamento ou não em relação aos mesmos; 2. Principais autores citados durante a explanação da metodologia: se somente os clássicos, se eram mencionados outros autores, inclusive de outras correntes da $A D ; 3$. A relação entre teoria e objeto empirico: se os aspectos teóricos estavam ou não relacionados com exemplos de análise; 4. Como era realizada a descrição do processo metodológico: se ocorria de forma genérica ou de forma explícita, descritiva, realizada através de exemplos da análise.

\subsection{Mapeando o processo metodológico do corpus}

Todos os aspectos que compuseram o mapeamento foram identificados exclusivamente nas seções dos artigos que se referiam ao aspecto metodológico da ADP, a partir dos quatro critérios mencionados.

1. Em relação aos principais conceitos utilizados, existe unanimidade nos artigos no que se referem ao discurso, à formação discursiva, formação ideológica, posição-sujeito, arquivo, condições de produção, corpus, interpretação, enunciado, efeitos de sentido, interdiscurso, memória, esquecimento e sujeito. Outros conceitos são desenvolvidos de acordo com o foco de análise de cada artigo, a titulo de exemplificação citamos: acontecimento histórico (A/2011), deslocamento (A/2009), dialética (A/2019), dito e já-dito (A/2019), efeito metafórico (A/2019), equívoco (A/2006), esquecimentos 1 e 2 (A/2019), estrutura (A/2019), formação social (A/2019), funcionamento linguístico (A/2019), gesto de interpretação $(A / 200 ; A / 2019)$, heterogeneidade (A/2011), identificação/desidentificação $(A / 2009)$, intradiscurso $(A / 2009 ; A / 2006)$, interpelação ideológica (A/2019), marcas linguísticas (A/2006, $A / 2019)$, metáfora (A/2009), metonímia (A/2009) e paráfrase (A/2009; A/2019). Portanto, os conceitos fundantes da $A D$ circulam em todos os artigos, alguns num nível superficial, no sentido de apresentar o conceito sem aprofundamento reflexivo, e/ou apenas citar os conceitos sem desenvolver seu significado, pressupondo que ele é de domínio teórico do leitor. O artigo A/2019 se destaca por ser o único a apresentar aprofundamento na reflexão sobre os conceitos, exemplificando-os por meio do material empírico utilizado para análise. Além disso, neste artigo se encontram os conceitos de paráfrase e polissemia como núcleos que conduzem o eixo da análise, demonstrando que não é possível trabalhar 
com todos os conceitos da ADP ao mesmo tempo. Assim, ao escolher o objeto de estudo do pesquisador, ele também elege conceitos fundamentais que serão problematizados junto com o objeto empírico. Isso não significa que os demais conceitos da ADP não sejam evocados, serão acionados sempre que necessário, pois estão inter-relacionados.

2. No que diz respeito aos autores citados durante o texto do artigo e na metodologia, existe uma unanimidade em mencionar Pêcheux e Orlandi. Além destes, outros autores são citados sem apresentar predominancia, tais como: Indursky (A/2019), Leandro-Ferreira (A/2006; A/2019), Courtine (A/2015; A/2011), Ernst-Pereira (A/2019), Serrani (A/2009), entre outros. Também foi possível identificar o uso de autores que, na nossa concepção, fazem parte de "correntes" diferentes da ADP, mas são tratados como se a integrassem. Nos artigos A/2011 e A/2015, por exemplo, são utilizados os conceitos de enunciado e formação discursiva de Foucault. É indiscutível a influência deste autor para ADP. No entanto, Pêcheux reelabora estes conceitos a partir de sua própria perspectiva, ressignificando-os. Existe uma diferença epistemológica importante que deve ser considerada e que coloca ambos os autores em filiações diferentes, pois, para Pêcheux, o materialismo histórico é constitutivo de sua teoria, sendo a relação sócio-histórica, centrada na luta de classes, um dos elementos que compõem esta abordagem. Na teoria de Foucault, a luta de classes não é uma questão a ser considerada. Esse aspecto não é um apêndice, mas uma diferença de identidade que distingue as teorias, que não podem ser anunciadas como se fossem pertencentes a uma mesma perspectiva. $O$ analista de discurso com filiação pecheutiana deve ter esse cuidado. Isso é o que chamamos de coerência epistemológica, que define as filiações e identidades associadas às teorias. No artigo A/2017 também existe o uso correlato entre Pêcheux, Charaudeau e Maingueneau, sem explicitar as devidas diferenças.

3. Outro aspecto mapeado foi a relação da teoria com o objeto empírico de análise. Dois artigos não apresentam esta relacão, enfatizando apenas o dispositivo teórico, A/2017 e A/2015. Em A/2009 e A/2006, existe uma menção aos objetos empíricos (um na área de aplicação ensino-aprendizagem de segunda língua, e o outro o discurso pedagógico na relação com alunos de curso superior), porém, não desenvolvem um exemplo ou exercício de análise. Dois artigos relacionam a teoria com o objeto empírico para demonstrar a relação entre os pressupostos teóricos e os metodológicos. A/2011 apresenta um exercício utilizando imagens da mídia impressa veiculadas à revista Veja, enquanto A/2019 exemplifica o processo metodológico através do discurso feminista.

4. Em relação à descrição do processo metodológico, todos se apresentam de forma singular, sendo possível realizar dois agrupamentos. O primeiro abrange os artigos que comentam de forma geral o dispositivo analitico, sem explicitar o procedimento realizado; enquanto o segundo o explicita. No primeiro grupo, encontramos 02 artigos. A/2017 apresenta um trabalho com conceitos gerais da ADP, sem a explicitação do processo metodológico, muito embora o título deste artigo inclua "metodologia". Os conceitos são tratados como categorias de análise, e o ato de explicitá-los é entendido como suficiente para dar conta da metodologia. Na mesma direção, A/2009 realiza a descrição de alguns conceitos da ADP, mas que também são chamados de categorias de análise. Embora este autor tenha se proposto a analisar 3 trabalhos (2 teses e 1 dissertação sobre o aspecto metodológico), por meio do que chama de "categoria", as mesmas não são relacionadas aos respectivos trabalhos. Neste sentido, o autor de A/2009 entende que a metodologia pode ser caracterizada pelo uso de categorias teóricas a 
priori. Destacamos o cuidado que deve ser tomado ao se referir à "categoria", pois este termo é predominantemente característico da análise de conteúdo, o que por si só pode gerar equívocos conceituais e metodológicos.

Neste primeiro grupo, foi possível constatar que embora todos os artigos mencionem a metodologia, nem todos dão visibilidade ou descrevem o processo realizado, ou seja, ela não é descrita, apenas mencionada. No segundo grupo, encontramos artigos que claramente explicitam a metodologia. A/2015 revela um processo metodológico que se baseia na primeira fase da ADP. Enfoca a metodologia por meio de 03 níveis: o primeiro é a "superfície linguística"; o segundo, o "objeto discursivo"; e o terceiro, o "processo discursivo".

Estes níveis estão relacionados à Análise AAD-69. Na década de 1980, porém, esta mesma metodologia é revista e abandona-se a ideia de usar uma padronização de análise espelhada na codificação sistemática, característica da linguagem informática. No texto "A análise de discurso: tres épocas" Pecheux (1983), caracteriza-as da seguinte forma: a primeira explorava os aspectos metodológicos a partir da noção de "maquinaria discursivoestrutural" (p. 311); a segunda caracterizava a "justaposição dos processos discursivos" (p. 313); e, por último, a "emergência de novos procedimentos da AD" (p. 315). Cabe mencionar que esta caracterização em tres épocas não tem sido utilizada, de forma a romper com uma ideia de fragmentação da teoria. No artigo A/2011 são explicados os aspectos a serem observados na metodologia: organização do corpus em que serão realizados os recortes (enquanto unidade discursiva); análise dos enunciados, estabelecendo relações com as condições de existência do mesmo (sua produção na história); a correlação com outros enunciados; a memória que é retomada e os efeitos de sentido produzidos no contexto. $O$ texto realiza a interpretação que se volta sobre a opacidade, as heterogeneidades e as contradições do discurso. O trabalho apresenta um exercício de análise com imagem e os aspectos metodológicos, que também identificamos em função do tipo de corpus selecionado.

Mais especificamente, tarta-se da seleção do corpus (duas imagens); indicação do título do artigo e da revista, contextualizando as imagens a partir do contexto histórico em que são produzidas; descrição da imagem; referência às cores utilizadas; explicitação da relação entre a imagem e a memória social; interpretação dos enunciados; apresentação de algumas interlocuções teóricas; e identificação das ironias que a imagem produz. No artigo A/2006 são explicitados metodologicamente os seguintes aspectos: a constituição do corpus; entrevista; transcrição; várias leituras das entrevistas; identificação do eixo temático; 
exploração das marcas linguísticas ou do discurso, relacionando-as com o contexto sóciohistórico e com as condições de produção; estabelecimento de recortes discursivos, caracterizando as regularidades na FD; interpretação do interdiscurso e do intradiscurso. Apenas A/2019 aprofundou o procedimento metodológico, constituído a partir de sete etapas: I) definição do objeto de estudo, considerando as condições de produção, a configuração da formação discursiva e a definição do enunciado; II) delimitação do tema, das condições de produção, da composição do arquivo e diálogo permanente com o referencial teórico; III) constituição do arquivo, coleta e seleção dos textos; IV) "leituratrituração do material coletado", escolha das sequências discursivas compondo o recorte do corpus, fase em que ocorre a passagem da superfície linguística para o objeto discursivo; V) articulação da sequência discursiva com a teoria; $\mathrm{VI}$ ) descrição da estrutura das sequências recortadas, procurando identificar se os enunciados remetem a outras formações discursivas; VII) caracterização das formações discursivas a partir da relação entre paráfrase e polissemia. Enfim, de ambos os grupos podemos afirmar que a metodologia de análise da ADP existe e deve ser explicitada, dando visibilidade científica ao processo. A síntese do mapeamento apresentado até o momento é demonstrada através da tabela ilustrada mais abaixo. Na primeira coluna, estão listados os quatro critérios identificados enquanto regularidade nos artigos; na segunda, apresentamos o desdobramento destes critérios; e, nas colunas seguintes, a marcação do que foi encontrado em cada artigo/data. Esta tabela possibilita visualizar a análise e perceber as interpretações dos resultados, permitindo ao leitor obter um panorama de comparação sistemática sobre o corpus analisado.

Tabela 1. Síntese do mapeamento

\begin{tabular}{l|l|c|c|c|c|c|c}
\hline Critérios & Especificações & $\mathrm{A} / 2006$ & $\mathrm{~A} / 2009$ & $\mathrm{~A} / 2011$ & $\mathrm{~A} / 2015$ & $\mathrm{~A} / 2017$ & $\mathrm{~A} / 2019$ \\
\hline \multirow{2}{*}{$\begin{array}{l}\text { 1. Principais } \\
\text { conceitos }\end{array}$} & Principais ADP & $\mathrm{X}$ & $\mathrm{X}$ & $\mathrm{X}$ & $\mathrm{X}$ & $\mathrm{X}$ & $\mathrm{X}$ \\
\cline { 2 - 8 } & Específicos/nucleadores & $\mathrm{X}$ & $\mathrm{X}$ & $\mathrm{X}$ & & & $\mathrm{X}$ \\
\hline
\end{tabular}




\begin{tabular}{|c|c|c|c|c|c|c|c|}
\hline & Com aprofundamento & & & & & & $\mathrm{X}$ \\
\hline \multirow{3}{*}{$\begin{array}{l}\text { 2. Principais } \\
\text { autores }\end{array}$} & Clássicos ADP & $\mathrm{X}$ & $\mathrm{X}$ & $\mathrm{X}$ & $\mathrm{X}$ & $\mathrm{X}$ & $\mathrm{X}$ \\
\hline & Outros autores ADP & $\mathrm{X}$ & $\mathrm{X}$ & $\mathrm{X}$ & $\mathrm{X}$ & & $\mathrm{X}$ \\
\hline & Outras correntes AD & & & $\mathrm{X}$ & $\mathrm{X}$ & $\mathrm{X}$ & \\
\hline \multirow{3}{*}{$\begin{array}{l}\text { 3. Relação } \\
\text { teoria e } \\
\text { objeto } \\
\text { empírico }\end{array}$} & $\begin{array}{l}\text { Não relaciona ênfase } \\
\text { teórica }\end{array}$ & & & & $\mathrm{X}$ & $\mathrm{X}$ & \\
\hline & $\begin{array}{l}\text { Não relaciona, mas } \\
\text { menciona objeto empírico }\end{array}$ & $\mathrm{X}$ & $\mathrm{X}$ & & & & \\
\hline & Relaciona teoria e análise & & & $\mathrm{X}$ & & & $\mathrm{X}$ \\
\hline \multirow{2}{*}{$\begin{array}{l}\text { 4. Descrição } \\
\text { metodológica }\end{array}$} & Geral, sem explicitar & & $\mathrm{X}$ & & & $\mathrm{X}$ & \\
\hline & Específico e exemplificado & $\mathrm{X}$ & & $\mathrm{X}$ & $\bar{X}$ & & $\mathrm{X}$ \\
\hline
\end{tabular}

\section{CONCLUSÕES}

É unânime em toda a literatura sobre ADP e no corpus empírico analisado, que não existe neste campo uma metodologia de análise pronta, sequencial. Por isso, a ADP não pode ser considerada como aplicação de uma técnica, ela é uma disciplina científica que produz conhecimento teórico próprio. Ao mesmo tempo, isso não quer dizer que não exista na ADP uma metodologia. Ela não pode ser padronizada, mas os analistas, ao descreverem seus processos de análise, permitem identificar que existem regularidades e singularidades no processo. Ou seja, existe um fio condutor, que dá identidade e caracteriza o dispositivo analitico da ADP a partir do quadro epistemológico de referência. A separação entre teoria e método poderá se tornar apenas um procedimento pedagógico para melhor compreensão da própria teoria. Entretanto, na práxis da produção do conhecimento, são indissociáveis, já que nem sempre é possível determinar quando se inicia um e outro. Assim, os dispositivos teórico e o analitico se entrecruzam, pois a teoria determina os parâmetros epistemológicos, e o objeto empírico tira a teoria do âmbito do abstrato, fazendo com que se entre no campo da prática discursiva. Isso não quer dizer que a ADP negue a metodologia. Pelo contrário, é possível perceber um procedimento em que os analistas cada vez mais estão preocupados em dar a ela visibilidade. Uma analogia a este entrelaçamento é a trança. É desta forma que o procedimento metodológico se constitui na $\mathrm{ADP}$, um permanente entrelaçamento entre o dispositivo teórico e o empírico. É importante compreender que este procedimento é passível de constantes alterações. Assim como o discurso é tido como a possibilidade de sempre haver outros sentidos, a metodologia deve ser compreendida como estado "em construção": sempre haverá aí outro caminho possível de ser percorrido pelo analista de discurso. Sendo a metodologia da ADP um entrelaçamento do dispositivo teórico com o dispositivo analitico, o resultado deste estudo permitiu identificar dois parâmetros utilizados 
nos artigos: primeiro, quando ocorre uma exposição distinta entre o dispositivo teórico e o dispositivo analitico, oportunizando ao leitor uma visibilidade de como o processo de análise e sua interlocução com a teoria ocorrem. Isso se aplica aos artigos A/2015, A/2011, A/2006 e A/2019, em que, ao se expor o quadro teórico, os autores o correlacionam ao descrito no exercício de análise. A interdependência é clara e, mais importante, existem coerência e visibilidade do processo metodológico.

O segundo parâmetro ocorre quando o analista considera que discorrer sobre a teoria já é suficiente para dar conta da metodologia, como se esta se realizasse apenas usando a explicação dos conceitos. Neste caso, acaba-se desenvolvendo apenas os conceitos teóricos, como se a metodologia compulsoriamente se fizesse presente. Embora se trate de trabalhos científicos com enfoque específico na discussão sobre a metodologia de pesquisa, nos artigos A/2017 e A/2009 ela não é descrita, resultando na invisibilidade da mesma, o que pode sugerir ao leitor a inexistência da metodologia. Em consequência disso, o título dos trabalhos (sobre metodologia) criam uma expectativa no leitor de que, após a leitura, haverá um exemplo de como proceder metodologicamente, o que não ocorre. Na ADP, cada processo metodológico poderá ser diferente do outro. O que é importante e o que nos parece fundamental é o analista descrever o processo percorrido, de forma que a metodologia seja abordada e considerada tão importante quanto os demais aspectos teóricos mobilizados no trabalho. Com isso, estamos dizendo que o dispositivo analitico deve receber a mesma importância que o dispositivo teórico, de forma que o entrelaçamento de ambos se torne visível. Ao mesmo tempo em que os procedimentos metodológicos da ADP não podem ser concebidos como a aplicação de uma técnica, eles devem ser visíveis ao leitor. Isso reafirma o uso do termo dispositivo teórico-analitico, no sentido de que são esferas distintas, mas, ao mesmo tempo, inseparáveis. O hífen representa não apenas o "e" inclusivo, mas "ser" inclusivo, o dispositivo é (do verbo ser) constituído de forma entrelaçada pelas duas dimensões, compondo um processo dialético. Refletir sobre a metodologia na pesquisa significa pensar sobre como a mesma é visibilizada nos trabalhos acadêmicos. Geralmente, os trabalhos utilizam um modelo de base positivista e estruturalista, quando os primeiros capítulos são teóricos e os demais destinados aos resultados da análise. Existe uma clara dicotomia entre o teórico e o analítico. Na ADP, esta lógica não se aplica, em decorrência do processo dialético que caracteriza a relação entre teórico e metodológico. Sugere-se que nos trabalhos em ADP, desde a introdução até as conclusões, o teórico e analitico sejam inseparáveis. Como fazê-lo? Eis o desafio do analista de discurso. 


\section{REFERÊNCIAS}

Courtine, J. (2016). Definição de orientações teóricas e construção de procedimentos em análise do Discurso. Policromias, junho, 2016, 14-35. Disponível em: https://bit.ly/2UE18gM

Fernandes, C., Vinhas, L. (2019). Da maquinaria ao dispositivo teórico-analitico: a problemática dos procedimentos metodológicos da análise de discurso. Linguagem em (Dis)curso. 19(1), 1-13.

Mittmann, S. (2007). Discurso e Texto: na pista de uma metodologia de análise. In Indusrky, F., Leandro-Ferreira, M. C. Análise do discurso no Brasil: mapeando conceitos, confrontando limites. São Carlos, Claraluz.

Oliveira, L. A. (org.) (2013). Estudos do discurso: perspectivas teóricas. São Paulo: Parábola Editorial.

Pêcheux, M. (1983). A análise de discurso: três épocas, 311-318. Disponível em: https://bit.ly/2Y46pij

Pêcheux, M. (1990). Análise automática do discurso. In Gadet, F., Hak, T. (org). Por uma análise automática do discurso: uma introdução à obra de Michel Pêcheux. Campinas: Editora da UNICAMP.

Pêcheux, M. (1997). Semântica e discurso: uma crítica à afirmação do óbvio, 3. ed. Campinas: Editora da UNICAMP.

Pêcheux, M. (2002). O Discurso: estrutura ou acontecimento, 3. ed., Campinas, São Paulo: Pontes.

Trivinos, A. (1987). Introdução à pesquisa em ciências sociais: a pesquisa qualitativa em educação, o positivismo, a fenomenologia, o marxismo. São Paulo: Atlas. 